\section{Reimar Banis}

In der Auseinandersetzung zwischen Schulmedizin und Komplementärmedizin wird häufig mit dem Placebobegriff operiert. Im Deutschen Ärzteblatt kann man lesen: «Placeboeffekte machen wahrscheinlich einen Teil, wenn nicht die Gesamtheit der Wirkung von Alternativ- und Komplementärmedizin aus. Da die Verabreichung ... aber einen Scheintatbestand schafft, ist ... zu prüfen, ob eine gezielte Placebogabe nicht ... eine Täuschung des Patienten darstellt» [1]. Ähnlich vernichtend äussert sich der Berner Immunologe Beda Stadler, wenn er behauptet: «Homöopathie ist Voodoomedizin aus Wasser und $\mathrm{Zu}$ cker» [2]. Die aggressive Auseinandersetzung dreht sich darum, was medizinisch richtig und sinnvoll und auch letztlich finanzierbar ist. Wer Placebos verabreicht, handelt in den Augen der Kritiker falsch, tut Sinnloses und verschleudert Versichertengelder. Die Frage ist, ob das tatsächlich stimmt.

Homöopathie gilt heute vor allem deshalb als umstritten, weil sie schlicht noch nicht genügend erforscht ist. Da man sie an den Universitäten von vornherein für «Unsinn» hält, wird sie erst gar nicht der Erforschung für

\title{
Ist Homöopathie bloss ein Placebo?
}

würdig gehalten. Gute klinische Studien kosten über zwei Millionen Euro und mehr, was das begrenzte Budget vieler Naturheilfirmen sprengt. Ausserdem zeigen neueste Untersuchungen, dass es eine Tendenz («Bias») zu Resultaten gibt, die der Studienleiter erwartet. Skeptiker «beweisen» daher mit ihren Studien bloss ihre Annahme, dass sowieso alles «Voodoo» sei. Doch trotz aller Widerstände existiert bereits eine ernstzunehmende Homöopathieforschung, die erfolgreich verlaufende klinische Studien und sogar positive Metastudien vorweisen kann (allerdings noch nicht in genügender Zahl), was angesichts der dargestellten ungünstigen Umstände umso mehr erstaunt.

Meist wird die Heilkraft von Placebos grösser eingeschätzt, als sie tatsächlich ist. Untersuchungen von Peter C. Gøtzsche et al. [3] im Rahmen einer grossen Meta-Studie zur Placebogabe fanden heraus, dass sie kaum wirken. Gøtzsche schreibt: «In den Fällen, in denen die klinischen Resultate der Placebos auf einer binären Skala gemessen worden waren - wie beispielsweise nach dem Grundsatz Besserung/keine Besserung -, konn- ten wir keinerlei Placebo-Effekte feststellen. Aus diesem Grunde widerlegt unsere Untersuchung die Behauptung, die alleinige Verabreichung von Placebos an Patienten könne starke klinische Wirkungen zur Folge haben». Eigene ärztliche Erfahrungen entsprechen dem Studienergebnis. In den seltenen Fällen, in denen ich tatsächlich nur Placebos verordnet hatte, war absolut nichts passiert. Das ist bei der Homöopathie, mit der ich in eigenen Studien positive Therapieeffekte von über $80 \%$ erzielen konnte, jedoch völlig anders. Ein solches Ergebnis spricht gegen eine blosse Placebowirkung, die nach dem akademischen Common Sense unter 40\% oder gemäss Gøtzsche sogar bei nahezu Null liegt.

\section{Literatur}

1 Breidert M, Hofbauer K: Placebo: Missverständnisse und Vorurteile. Dtsch Ärztebl 2009; 106:751-755.

2 Stadler BM: Bundesrat mit Nebenwirkungen. Die Weltwoche, Ausgabe 10, 10.03.2010. www.weltwoche.ch.

3 Gøtzsche PC, Hróbjartsson A: Is the placebo powerless? An analysis of clinical trials comparing placebo with no treatment. N Engl J Med 2001;344:1594-1602.

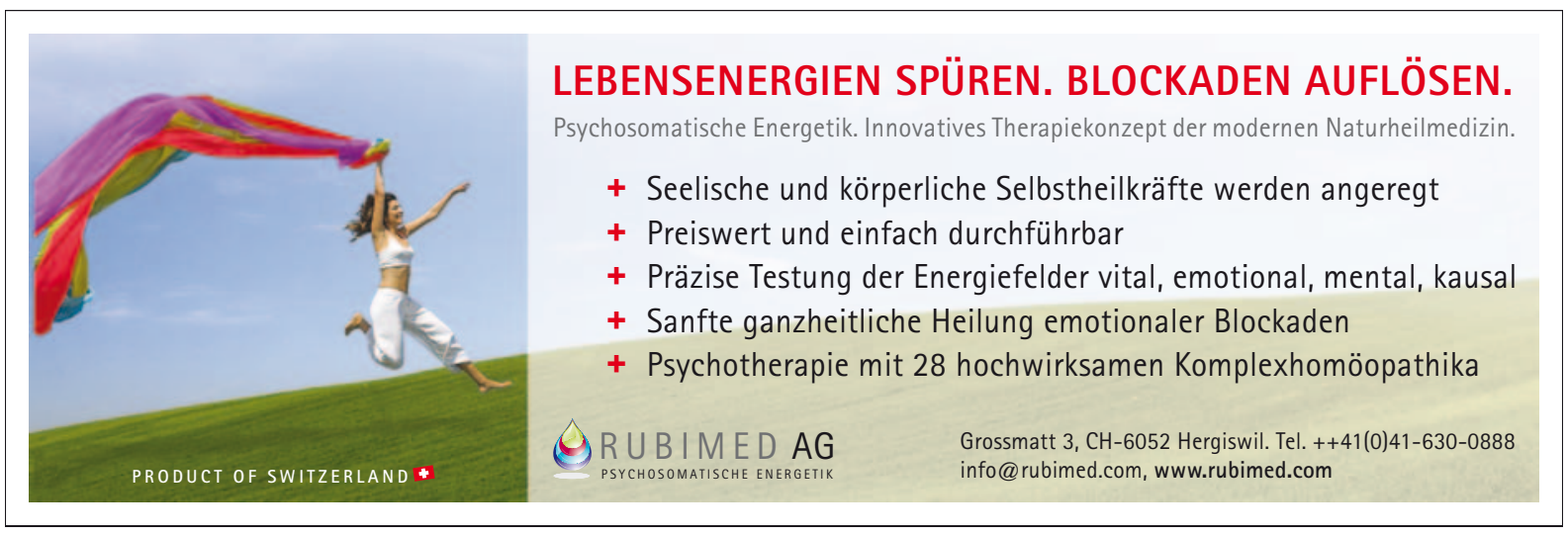

\section{KARGER}

Fax +49761 4520714 Information@Karger.d www.karger.com (c) 2010 S. Karger GmbH, Freiburg www.karger.com/szg
Dr. med. Reimar Banis

Rubimed AG

Grossmatt 3, 6052 Hergiswil, Schweiz

Tel. +41 416300888

drbanis@rubimed.com 